\title{
Graft versus host disease associated with blood transfusion
}

\author{
Anindya Gupta*1 \\ ${ }^{1}$ NottinghamUniversity Hospitals, United Kingdom
}

Graft versus Host Disease (GVHD) typically occurs after hematopoetic stem cell transplantation (HSCT) as the donor lymphocytes attack antigen presenting cells with a different HLA haplotype in host tissues, typically in the skin, liver and gastrointestinal tract. But can you get GVHD in non-transplant subjects? Normally, blood transfusions would not be expected to cause GVHD, as the recipient's immune system would destroy lymphocytes in the donor blood. However, GVHD has been demonstrated after blood transfusion in subjects who have not had a transplant. This typically occurs in two settings. Firstly, the subject is immunosuppressed, either because of an underlying T-cell disorder, as in children, or because of chemotherapy or radiotherapy for hematologic or solid cancer $[1,2]$. Hence the donor lymphocytes are free to run amok. The second setting is unique and occurs in immunocompetent subjects. This typically happens when a subject who is heterozygous for a HLA antigen receives a blood transfusion from a donor who is homozygous for that HLA antigen [3]. Thus, the host's lymphocytes do not recognise the blood donor's lymphocytes as foreign, but the donor lymphocytes recognise the "mismatched" HLA antigen in the host tissues as alien. This kind of mishap is likely to occur when there is limited genetic variability in the population, as in Japan, or when the blood donor is a family member, particularly if there is a high rate of consanguinity, thus causing shared HLA antigens, such as in rural Turkey [4] or on the subcontinent [5]. Unlike transplantion associated GVHD, transfusion associated GVHD is almost always fatal [6-8] This is because apart from attacking the skin, liver and GI tract, lymphocytes in the donor blood also attack the host's bone marrow, causing aplasia. Remember, that in HSCT, the marrow has been ablated, and replaced by the donor marrow, which will therefore not be attacked by the graft lymphocytes.

Transfusion associated GVHD starts 2-30 days after transfusion [9], is usually mild and insidious in onset and is therefore often not recognised, and is usually attributed to the underlying disease. It starts with fever and rash, which can become erythrodermatous in severe cases, and proceeds to vomiting, severe diarrhoea, right upper quadrant pain, deranged LFTs, and pancytopenia [10].

Transfusion associated GVHD can be caused by transfusing whole blood, packed RBC, platelets, leucocytes and fresh unfrozen plasma. It does not occur when transfusing deglycerolated, frozen $\mathrm{RBC}$ or cryoprecipitate or FFP.

Copyright: $(2017$ Gupta A. This is an open-access article distributed under the terms of the Creative Commons Attribution License, which permits unrestricted use, distribution, and reproduction in any medium, provided the original author and source are credited.
Diagnosis can be made by a skin biopsy and by demonstrating that the circulating lymphocytes are the donor's rather than the host's [11].

This devastating complication can be prevented by gammairradiating donor blood in the following 4 instances- in immunosuppressed subjects, in subjects who have had HSCT (although GVHD here would not affect the marrow), in instances where the blood donor is a relative and in HLA-matched platelet transfusions [12].

\section{References}

1. Uchida S, Tadokoro K, Takahashi M, Yahagi H, Satake M, et al. (2013) Analysis of 66 patients definitive with transfusion-associated graft-versus-host disease and the effect of universal irradiation of blood. Transfus Med 23: 416-422.

2. Sebnem Kilic S, Kavurt S, Balaban Adim S (2010) Transfusion associated graft-versushost disease in severe combined immunodeficiency. J Investig Allergol Clin Immunol 20: $153-156$.

3. Shivdasani RA, Anderson KC (1994) HLA homozygosity and shared HLA haplotypes in the development of transfusion-associated graft-versus-host disease. Leuk Lymphoma 15: 227-234. [Crossref]

4. Agbaht K, Altintas ND, Topeli A, Gokoz O, Ozcebe O (2007) Transfusion-associate graft-versus-host disease in immunocompetent patients: case series and review of the literature. Transfusion 47: 1405-1411. [Crossref]

5. Sohi I, Jacob S (2005) Transfusion associated GVHD. Indian J Pediatr 72: 533-535. [Crossref]

6. Gilstad C, Roschewski M, Wells J, Delmas A, Lackey J, et al. (2012) Fatal transfusionassociated graft-versus-host disease with concomitant immune hemolysis in a group A combat trauma patient resuscitated with group $\mathrm{O}$ fresh whole blood. Transfusion 52: 930-935. [Crossref]

7. Patel KK, Patel AK, Ranjan RR, Shah AP (2010) Transfusion associated graft versus host disease following whole blood transfusion from an unrelated donor in an immunocompetent patient. Indian J Hematol Blood Transfus 92-95.

8. Sunul H, Erguven N (2013) Transfusion-associated graft-versus-host disease. Transfus Apher Sci 49: 331-333. [Crossref]

9. Brubaker DB (1986) Transfusion-associated graft-versus-host disease. Hum Pathol 17: 1085-1088. [Crossref]

10. Aoun E, Shamseddine A, Chehal A, Obeid M, Taher A (2003) Transfusion-associated GVHD: 10 years' experience at the American University of Beirut-Medical Center. Transfusion 43: 1672-1676.

11. Sage D, Stanworth S, Turner D, Navarrete C (2005) Diagnosis of transfusion-associated graft-vs.-host disease: the importance of short tandem repeat analysis. Transfus Med 15: 481-485.

12. Fast LD (2012) Developments in the prevention of transfusion-associated graft-versushost disease. Br J Haematol 158: 563-568. [Crossref]
Correspondence to: Anindya Gupta, Nottingham University Hospitals, United Kingdom, E-mail: Dhondy@hotmail.com

Received: February 05, 2017; Accepted: February 28, 2017; Published: March 03, 2017 